\title{
Comment on the New Indian Injection Technique Recommendations: Critical Appraisal of the Real- World Implementation of the Current Guidelines
}

\author{
Felice Strollo · Sandro Gentile
}

Received: March 16, 2017 / Published online: April 26, 2017

(C) The Author(s) 2017. This article is an open access publication

\begin{abstract}
With an eye on the sequence of two Indian papers concurrently published in Diabetes Therapy, this paper analyzes skin differences among races and points to a lack of organized structured education sessions as the main cause of the high prevalence of lipodystrophy (LD) and consequent poor metabolic control. Only half of all insulin-treated patients reach their therapeutic targets worldwide. The factors involved in this are manifold, including the choice of overlong and repeatedly reused needles, as well as a failure to systematically rotate injection sites, all of which lead to skin LD. Regularly issued guidelines and expert recommendations provide suggestions about how to correct poor injection techniques, but LD still occurs at a high rate and is associated with poor metabolic control, a high risk of complications, frequent severe hypoglycemic episodes, and huge health and social costs. Poor knowledge of subcutaneous tissue anatomy and the physiological response to insulin injection by both health care personnel and patients may
\end{abstract}

F. Strollo $(\bowtie)$

Endocrinology and Metabolism Unit, Elle-di, Rome, Italy

e-mail: felix.strollo@gmail.com

S. Gentile

Department of Clinical and Experimental Medicine,

2nd University of Naples, Naples, Italy contribute to this problem. Moreover, differences in body structure among the races present in our multiethnic societies must be taken into account when choosing needle length and shooting technique in order to avoid accidental intramuscular injections.

Keywords: Diabetes mellitus; Injection technique; Insulin; Needles; Recommendations

\section{COMMENTARY}

The authors of two papers that have recently been published online in this journal $[1,2]$ compared data on an Indian population with corresponding data from 41 other countries (denoted the rest of the world, ROW), based on the results of an Injection Technique Questionnaire (ITQ) survey performed throughout India and involving 1011 patients, which provided information on overall injecting practices, injection complications, and health care professional education in their country. While diligently describing possible differences between the insulin delivery technique applied in India and that used in the rest of the world, they were able to shed light on some issues that may be easily extended to a global context.

Their overall results may be summarized as follows: 
- Mean HbA1c was 8.6, and the total daily dose (TDD) of insulin was lower than in the ROW (probably due to the fact that BMI values were $1.5-3$ units lower as well, which increased the risk of intramuscular (IM) injections)

- Needle reuse and the number of times that needles were used were much higher, and thighs (associated with riskier IM injections) were chosen for injections more often in India than in the ROW

- More than a quarter of Indian insulin users described lesions consistent with lipohypertrophy (LH) at their injection sites; approximately 1 in 5 users were found to have LH by the examining nurse, and about half of them had suffered painful injections

- Despite a specialized educational approach, many of the patients reported that they had not been trained well enough and had seldom had their sites checked during periodic visits

Therefore, importantly, those two papers clearly show that appropriate injection technique is a major issue in the real world, which is why we were driven to write the following extended commentary that simultaneously attempts to provide the readers of this journal with an updated overview of this topic.

\section{Compliance with Ethics Guidelines}

This article is based on previously published investigations and does not involve any new studies of human or animal subjects performed by the authors.

\section{Unmet Needs of Insulin Therapy}

Even though some 90 years have passed since insulin was first commercialized, a fairly large number of patients are still not using an appropriate injection technique. Moreover, although advances in technology have made new syringes, pens, and increasingly short, thin, and sharp needles available, insulin treatment has not yielded the expected results-many issues have not yet been resolved, and there are still too many unmet needs. As a matter of fact, only half of all insulin-treated patients reach their therapeutic targets worldwide [3], so it is crucial that insulin is routinely injected into healthy subcutaneous tissue.

\section{How are the Recommendations Applied?}

The factors involved in nonoptimal and quite often unpredictable insulin absorption have been identified during the last 10 years or so [4-6]: (1) the use of overlong needles; (2) frequent needle reutilization; (3) failure to systematically rotate injection sites; (4) missed skinfold pinching $/ 45^{\circ}$ angle needle injection in thin people; (5) failure to systematically inspect/palpate LH skin nodules before injections; (6) patient underestimation of guidelines on correct insulin injection; (7) a lack of preliminary structured education concerning the best injection modalities; (8) missed regular patient refresher courses; and (9) a lack of regular nurse examinations at which skin lesions and/or inappropriate injection modalities are identified. Indeed, these bad habits are widespread, and have been addressed by several scientific publications [6], including regularly issued guidelines and expert recommendations suggesting practical solutions for correcting behavior. However, LH is still frequent and is associated with clinical consequences, including poor metabolic control $[7,8]$, severe hypoglycemic episodes, and high health/social costs [9].

In addition, injections are often painful, thus reducing compliance to treatment. Therefore, to try to prevent pain and simplify the injection technique, shorter (4- and 5-mm) needles have been developed and commercialized and careful training is recommended. Nevertheless, patients and nurses still often use 8 -mm needles which exceed the thickness of the skin and subcutaneous fat and thus penetrate into the muscle. This is bound to cause poor glycemic control $[7,8]$, as discussed in greater detail in the next paragraph. 


\section{Body Structure and Skin} and Subcutaneous Tissue Anatomy

Over the last few decades, it has become increasingly apparent that body structure, funding, and the availability of updated devices or next-generation insulins vary markedly among International Diabetes Federation (IDF) member regions.

As far as skin and subcutaneous tissue (SCT) structure is concerned, several studies have highlighted that the average BMI is lower in adult or infant Asians than in the ROW $[1,2,10-14]$ (especially in Europeans [15-19]), as well as the existence of a positive correlation between SCT thickness and BMI. Because the skin and subcutaneous adipose layer are relatively thin in subjects with a low BMI, they are at a high risk for accidental intramuscular injections [10-14]. Considering the multiethnicity of Western societies, it is important to take this issue into account in Western populations.

In an ultrasound evaluation of an adult Chinese population [11], skin thickness showed only a minimal dependence on body site and on various demographic characteristics (including age, gender, type of diabetes, and BMI), whereas SCT appeared to be far more variable: its thickness was greater in women, at the abdominal level, and in patients with a high BMI. Studies of skin and SCT thicknesses in other Asian populations, such as Filipinos [12], Koreans [13], and Indians [14], yielded comparable results to those obtained for the Chinese population, whereas non-Asian populations had considerably higher BMIs in a major ultrasound-based study $[16,17]$.

Lower BMI values may also have contributed to the popularity of shorter insulin needles, as Indian patients become aware of the risks of IM injections with longer needles when the BMI is low.

Recent studies of a large population of adults with diabetes found that the skin thickness at the insulin injection site differed minimally with patient characteristics such as the BMI (i.e., obese patients had similar skin thicknesses to normal and thin patients) $[13,20]$. However, the same study showed that fat thickness (SC space) varied widely from one individual to another based on gender, BMI, and injection area. It highlighted the risk of IM injections, and showed that 4-mm needles presented the lowest risk of such injections. A study recently published in India confirmed those findings [16].

\section{Are Patients Provided with Structured Education or Simple Information?}

The other important issue that is raised by the papers from Indian authors $[1,2]$ is that reallife injection habits do not match the guidelines published in many countries, especially the latest recommendations published by the panel of experts attending the 2015 FITTER Congress in Rome [20]. Economic factors work against clinically appropriate solutions, as repeated reuse of the same needle is a widespread habit in Indian patients. That said, this practice appears to be highly prevalent worldwide due to not only financial constraints but also a dangerous mix of ignorance, opportunism, and laziness indulged in by both patients and operators. In everyday practice, structured education appears to be hardly (if ever) performed, as reported by a large number of both Indian [1, 2, 14] and Italian [16-18] patients. Sadly, there are also no guidelines suggesting how related knowledge should be reinforced by appropriate educational follow-up sessions that also give health care providers a chance to verify the injection habits of individual patients. Moreover, although professional educators are available for this purpose in several countries, in other countries doctors and nurses acting as self-learners often attempt to improvise the role of expert educators; after providing their patients with superficial information, they do not plan any periodic refresher or quality control sessions. The result is a widespread lipodystrophic phenomenon [7] and a high rate of seemingly inexplicable hypoglycemia and high glycemic variability that are closely related to poor injection techniques, which could eventually be prevented or reversed by experienced structured educational activities [7, 19, 21]. 


\section{CONCLUSIONS}

The variable yet high rate of localized insulin treatment complications reveals that proper injection technique recommendations are often either unknown or almost completely disregarded worldwide [7]. These unmet needs lead to high glycemic variability with frequent apparently unexplainable hypoglycemic episodes, which in turn trigger a series of negative consequences for glycemic control, quality of life, and health and social costs [22]. Recently published recommendations on this topic [20] are comprehensive and practical but have little chance of being implemented by many insulin-treated patients. Health care providers must realize that better and better insulins, injection systems, or advanced technologies are useless in the absence of effective structured educational programs which address how, what, and where the insulin shot should be given. Data provided by Indian colleagues that compare Indian patients to the rest of the world $[1,2]$ suggest that body structure varies significantly with ethnicity. This issue should therefore also be taken into account when personalizing treatment in terms of needle length in everyday clinical practice.

\section{ACKNOWLEDGEMENTS}

No funding or sponsorship was received for this publication. The authors of this manuscript meet the International Committee of Medical Journal Editors (ICMJE) criteria for authorship, take responsibility for the integrity of the work as a whole, and gave final approval for the version to be published.

Disclosures. Felice Strollo and Gentile Sandro have nothing to disclose.

Compliance with Ethics Guidelines. This article is based on previously published investigations and does not involve any new studies of human or animal subjects performed by the authors.
Data Availability. Data sharing is not applicable to this article, as no datasets were generated or analyzed during the current study.

Open Access. This article is distributed under the terms of the Creative Commons Attribution-NonCommercial 4.0 International License (http://creativecommons.org/licenses/ by-nc/4.0/), which permits any noncommercial use, distribution, and reproduction in any medium, provided you give appropriate credit to the original author(s) and the source, provide a link to the Creative Commons license, and indicate if changes were made.

\section{REFERENCES}

1. Indian Injection Technique Study. Population characteristics and injection practices. Diabetes Ther. 2017 (in press).

2. Indian Injection Technique Study. Injecting complications, education and the health care professional. Diabetes Ther. 2017 (in press).

3. De Cosmo S, Viazzi F, Pacilli A, Giorda C, Ceriello A, Gentile S, Russo G, Rossi MC, Nicolucci A, Guida P, Di Bartolo P, Pontremoli R, the AMD Annals Study Group. Achievement of therapeutic targets in patients with diabetes and chronic kidney disease: insights from the Associazione Medici Diabetologi Annals initiative. Nephrol Dial Transplant. 2015;30(9):1526-33.

4. WHO. Best practices for injections and related procedures toolkit. Geneva: WHO; 2010. http:// www.who.int/injection_safety/9789241599252/en/.

5. Hofman PL, Derraik JG, Pinto TE, Tregurtha S, Faherty A, Peart JM, Drury PL, Robinson E, Tehranchi R, Donsmark M, Cutfield WS. Defining the ideal injection techniques when using 5-mm needles in children and adults. Diabetes Care. 2010;33:1940-4. doi:10.2337/dc10-0871 (Epub 2010 Jun 28).

6. Spollett G, Edelman SV, Mehner P, Walter C, Penfornis A. Improvement of insulin injection technique: examination of current issues and recommendations. Diabetes Edu. 2016;42(4):379-94. doi:10.1177/0145721716648017 (Epub 2016 May 23).

7. Blanco M, Hernández MT, Strauss KW, Amaya M. Prevalence and risk factors of lipohypertrophy in 
insulin-injecting patients with diabetes. Diabetes Metab. 2013;39:445-53. doi:10.1016/j.diabet.2013. 05.006 (Epub 2013 Jul 22).

8. Gentile S, Agrusta M, Guarino G, Carbone L, Cavallaro V, et al. Metabolic consequence of incorrect insulin administration techniques in aging subjects with diabetes. Acta Diabetol. 2011;48:121-5.

9. Giorda CB, Ozzello A, Gentile S, Aglialoro A, Chiambretti A, Baccetti F, Gentile FM, Lucisano G, Nicolucci A. Rossi MC; HYPOS-1 Study Group of AMD. Incidence and risk factors for severe and symptomatic hypoglycemia in type 1 diabetes. Results of the HYPOS-1 study. Acta Diabetol. 2015;52:845-53. doi:10.1007/s00592-015-0713-4 (Epub 2015 Feb 12).

10. Sim KH, Hwang MS, Kim SY, Lee HM, Chang JY, Lee MK. The appropriateness of the length of insulin needles based on determination of skin and subcutaneous fat thickness in the abdomen and upper arm in patients with type 2 diabetes. Diabetes Metab J. 2014;38:120-33. doi:10.4093/dmj.2014. 38.2.120 (Epub 2014 Apr 18).

11. Wanga W, Guoa X, Shena G, Baib G, Weic Z, Liuc J, Hirschd L, Strauss K. Skin and subcutaneous tissue thickness at insulin injection sites in Chinese diabetes patients: clinical implications. Diabetes Metab. 2016;42:374-7.

12. Catambing, Villa M. Ultrasonographic measurement of skin and subcutaneous thickness at insulin injection sites among adult Filipinos with diabetes. JAFES. 2014;29:24-32.

13. Joo G, Sohng KY. Gluteal subcutaneous fat thickness measured by computed tomography as an estimate of proper gluteal intramuscular injections in Korean adults. J Korean Acad Nurs. 2010;40:247-54.

14. Jain SM, Pandey K, Lahoti A, Rao PK. Evaluation of skin and subcutaneous tissue thickness at insulin injection sites in Indian, insulin naïve, type- 2 diabetic adult population. Indian J Endocrinol Metab. 2013;17:864-70.

15. Gibney MA, Arce CH, Byron KJ, Hirsch L. Skin and subcutaneous adipose layer thickness in adults with diabetes at sites used for insulin injections: implications for needle length recommendations. Curr Med Res Opin. 2010;26:1519-30.

16. LoPresti D, Ingegnosi C, Strauss K. Skin and subcutaneous thickness at injecting sites in children with diabetes: ultrasound findings and recommendations for giving injection. Pediatr Diabetes. 2012;13:525-33.

17. Gentile S, Strollo F, Guarino G, Giancaterini A, Ames PRJ, Speese K, Guida P, Strauss K, on behalf of the AMD-OSDI Italian Injection Technique Study Group. Factors hindering correct identification of unapparent lipohypertrophy. J Diabetes Metab Disord Control. 2016;3(2):00065. doi:10.15406/ jdmdc.2016.03.00065.

18. Strollo F, Guarino G, Armentano V, Clemente G, Martedì E, De Riu S, Gaeta I, Corigliano G, Ceriello A, Gentile S, on behalf of AMD-OSDI Italian Study Group on Injection Techniques. Unexplained hypoglycaemia and large glycaemic variability: skin lipohypertrophy as a predictive sign. Diabetes Res Open J. 2016. doi:10.17140/DROJ-2-126.

19. Grassi G, Scuntero P, Trepiccioni R, Marubbi F, Strauss K. Optimizing insulin injection technique and its effect on blood glucose control. J Clin Transl Endocrinol. 2014;1:145-50.

20. Frid AH, Kreugel G, Grassi G, Halimi S, Hicks D, Hirsch LJ, Smith MJ, Wellhoener R, Bode BW, Hirsch IB, Kalra S, Ji L, Strauss KW. New insulin delivery recommendations. Mayo Clin Proc. 2016;91:1231-55. doi:10.1016/j.mayocp.2016.06. 010.

21. Gentile S, Guarino G, Giancaterini A, Guida P, Strollo F, AMD-OSDI Italian Injection Technique Study Group. A suitable palpation technique allows to identify skin lipohypertrophic lesions in insulin-treated people with diabetes. SpringerPlus. 2016;5:563. doi:10.1186/s40064-016-1978-y.

22. Giorda CB, Rossi MC, Ozzello O, Gentile S, Aglialoro A, Chiambretti A, Baccetti F, Gentile FM, Romeo F, Lucisano G, Nicolucci A; HYPOS-1 Study Group of AMD. Healthcare resource use, direct and indirect costs of hypoglycemia in type 1 and type 2 diabetes, and nationwide projections: results of the HYPOS-1 study. Nutr Metab Cardiovasc Dis. 2017;27(3):209-216. 